\title{
Resumos de Teses
}

Lesões ósseas no diagnóstico de neurofibromatose.

Autor: Marcos Pontes Muniz. Orientadora: Eny Maria Goloni-Bertollo. Tese de Doutorado. São José do Rio Preto: Famerp, 2004.

A neurofibromatose (NF), ou doença de von Recklinghausen, é uma das entidades genéticas com padrão de herança autossômica dominante mais freqüente na espécie humana, com incidência estimada em um caso para cada 3.000 habitantes. A NF apresenta grande variedade de manifestações clínicas, o que dificulta o diagnóstico. Na faixa pediátrica as manifestações clínicas podem não estar presentes, uma vez que a doença é de caráter progressivo e sistêmico. 0 exame radiológico, realizado por meio de radiografias simples dos grandes grupos ósseos, bem como o exame de ressonância magnética, podem contribuir para detectar alterações importantes e auxiliar no diagnóstico e tratamento precoce da doença. A associação de neurofibromas com outras neoplasias é freqüente e a incidência de neoplasias malignas nos pacientes com NF é cerca de quatro vezes maior que a população geral. O diagnóstico deve ser feito precocemente e os pacientes devem ser acompanhados ao longo de suas vidas, considerando que os tumores e demais lesões podem surgir em qualquer idade.

Com o objetivo de contribuir para o diagnóstico precoce e acompanhamento dos pacientes com NF, realizou-se investigação radiológica de 166 deles, os quais foram encaminhados pelo Centro de Atendimento em Neurofibromatose (Cepan), com radiografias simples do tórax, coluna, crânio e membros superiores e inferiores em duas incidências, em que foi observado que o local de maior acometimento é a coluna, sendo a escoliose a alteração mais freqüente. A erosão na parede posterior do corpo vertebral é uma alteração fre- qüente nos pacientes com NF e ausente nos pacientes da população em geral, e sua inclusão como lesão óssea característica é um critério consistente para auxiliar no diagnóstico da doença. Os dados estatísticos dos achados radiográficos prevalentes não encontrados na literatura foram: erosão dos arcos costais $(19,1 \%)$, peito escavado $(12,0 \%)$, massa mediastinal $(7,1 \%)$, erosão da parede posterior da coluna vertebral $(25,9 \%)$, aumento dos forames de conjugação $(18,9 \%)$, arqueamento dos membros $(5,1 \%)$, lesões císticas ósseas $(16,2 \%)$, afilamento cortical dos ossos longos (8,5\%), distúrbios do crescimento $(5,1 \%)$ e radioluscência do crânio (3,0\%).

\section{Rim multicístico displásico em crianças: seguimento ultra-sonográfico.}

Autor: Antonio Soares Souza.

Orientador: Giovanni Guido Cerri.

Tese de Doutorado. São Paulo: FMUSP, 2001.

O rim multicístico displásico (RMD) consiste de um aglomerado de cistos de vários tamanhos, sendo a segunda causa mais comum de massa abdominal no recém-nascido, após a hidronefrose. A necessidade de ressecção do RMD tem sido questionada, sendo que o acompanhamento ultra-sonográfico realizado após o diagnóstico tem demonstrado tendência à involução. Assim, o objetivo deste estudo foi avaliar a ocorrência de complicações, o comportamento do RMD e do maior cisto em relação ao tamanho no acompanhamento ultra-sonográfico e as alterações do rim contralateral.

Foram estudadas 52 crianças com RMD, com idade variando entre 1 e 277 dias $(36,7$ $\pm 28,7$ dias -44 casos) e 1 e 16,1 anos (7,2 $\pm 1,9$ anos -8 casos). Para análise do RMD considerou-se redução, desaparecimento e aumento abaixo, igual ou acima de $10 \%$. 0 comportamento do RMD foi estudado com curvas atuariais de Kaplan-Meier, avaliando a probabilidade de redução, desaparecimento ou aumento do RMD em meses de seguimento.

O RMD no seguimento ultra-sonográfico apresentou redução em 27 (51,9\%) pacientes e desaparecimento em $12(23,1 \%)$, aumento menor que $10 \%$ em $9(17,3 \%)$ e aumento acima ou igual a $10 \%$ em 4 (7,7\%). A curva de Kaplan-Meier mostrou, para o grupo total, probabilidade de $26,2 \%$ (erro padrão \pm $6,9 \%$ ) de permanecer livre de qualquer grau de redução ou desaparecimento do rim comprometido, cujo valor atingiu a $70,8 \%$ (erro padrão $\pm 8,1 \%$ ) para livres de desaparecimento em 48 meses de seguimento. A estimativa para permanecer livre de qualquer grau de aumento do rim afetado foi de $74,7 \%$ (erro padrão $\pm 7,6 \%$ ) no mesmo período. Foram observadas 22 anormalidades no rim contralateral de $16(30,1 \%)$ pacientes. Entre as 27 crianças submetidas a uretrocistografia miccional ou cistografia direta radioisotópica, 22,2\% apresentaram refluxo vesicoureteral. Dentre as outras anormalidades, foram encontradas estenose da junção pieloureteral $(7,7 \%)$, dilatação não obstrutiva do sistema pielocalicilar $(5,8 \%)$, rotação incompleta $(5,8 \%)$, divertículos calicinais $(3,8 \%)$, dilatação do sistema pielocalicilar e ureter proximal (1,9\%), cálculo renal $(1,9 \%)$ e dilatação do ureter (1,9\%). Anomalias associadas foram detectadas em dois pacientes, incluindo mielomeningocele e síndrome de Vater.

Em conclusão, não foram encontradas complicações em crianças com RMD no acompanhamento ultra-sonográfico. Constatou-se elevada probabilidade de redução do diâmetro ou desaparecimento do RMD durante seguimento ultra-sonográfico. 0 diâmetro do maior cisto apresentou comportamento semeIhante ao do RMD. O rim contralateral pode apresentar alterações em crianças com RMD com destaque para o refluxo vesicoureteral e estenose da junção pieloureteral. 